\title{
Surface-Active Agent
}

National Cancer Institute

\section{Source}

National Cancer Institute. Surface-Active Agent. NCI Thesaurus. Code C83486.

Any chemical that reduces the surface tension of the medium in which it is dissolved or lowers the interfacial tension between two immiscible phases. 